\title{
(2) OPEN ACCESS \\ Pulmonary arteriovenous malformations may be the only clinical criterion present in genetically confirmed hereditary haemorrhagic telangiectasia
}

\author{
Emily Anderson $\odot,{ }^{1,2}$ Lakshya Sharma $\odot,{ }^{3}$ Ali Alsafi $\odot,{ }^{4}$ Claire L Shovlin $\circledast^{2,3}$
}

\begin{abstract}
- Additional supplemental material is published online only. To view, please visit the journal online (http://dx.doi. org/10.1136/thoraxjnl-2021 218332)
\end{abstract}

${ }^{1}$ Department of Clinical Genetics, Liverpool Women's NHS Foundation Trust, Liverpool, UK

${ }^{2}$ Genomics England Respiratory Clinical Interpretation

Partnership (GeCIP), London, UK ${ }^{3}$ National Heart and Lung Institute, Imperial College London, London, UK

${ }^{4}$ Department of Imaging, Imperial College Healthcare NHS Trust, London, UK

\section{Correspondence to}

Professor Claire L Shovlin, National Heart and Lung Institute, Imperial Centre for Translational and Experimental Medicine, Imperial College London, Imperial College Hammersmith Campus, Du Cane Road, London W12 ONN, UK; c.shovlin@imperial.ac.uk

Received 8 October 2021 Accepted 14 January 2022
Check for updates

(C) Author(s) (or their employer(s)) 2022. Re-use permitted under CC BY-NC. No commercial re-use. See rights and permissions. Published by BMJ.

To cite: Anderson $E_{\text {, }}$ Sharma L, Alsafi A, et al. Thorax Epub ahead of print [please include Day Month Year]. doi:10.1136/

thoraxinl-2021-218332

\section{ABSTRACT}

Pulmonary arteriovenous malformations (PAVMs) result in preventable complications demanding specialty care. Underlying hereditary haemorrhagic telangiectasia (HHT) can be identified by genetic testing, if the diagnosis is considered. Retrospectively reviewing 152 unrelated adults with genetically confirmed HHT due to ACVRL1, ENG or SMAD4, we found that only 104/152 (68\%) met a clinical diagnosis of HHT with three Curaçao criteria. The genetic diagnostic rate was similar for patients with three $(104 / 137,76 \%)$ or one to two $(48 / 71,68 \%$; $\mathrm{p}=0.25)$ criteria. Of 83 unrelated probands with PAVM(s) and genetically-confirmed HHT, 20/83 (24\%) had few, if any, features of HHT. Enhanced clinical suspicion, as well as HHT genetic testing, is recommended if one or more PAVMs are present.

\section{INTRODUCTION}

Pulmonary arteriovenous malformations (PAVMs) are capillary-free vascular communications between pulmonary arteries and pulmonary veins, resulting in an anatomical intrapulmonary right-to-left shunt. ${ }^{1}$ PAVM prevalence was estimated by general population screening thoracic CT imaging at 38 per 100000 individuals in Japan (95\% CI 18 to 76 ), corresponding to $1 / 2631$ (95\% CI $1 / 1315$ to $1 / 5555){ }^{2}$ Although this seems high for respiratory clinical practice, the majority of PAVMs are asymptomatic and undiagnosed, ${ }^{1}$ despite continuous right-to-left shunting, which impairs gas exchange and places individuals at high risk of neurological complications from paradoxical emboli. ${ }^{13}$ Neurological risks are present whether or not the individual has symptoms from the PAVM(s). ${ }^{1}$ Details of appropriate management of patients with PAVMs are outlined in recent British Thoracic Society ${ }^{1}$ and Cardiovascular and Interventional Radiological Society of Europe ${ }^{4}$ statements.

Clinicians and patients might be aware that PAVMs can be a familial condition, most commonly due to hereditary haemorrhagic telangiectasia (HHT). HHT is a multisystemic vascular dysplasia, inherited as an autosomal dominant trait, and important to diagnose early because screening and interventions have led to reduced morbidity and mortality. ${ }^{5}$ If HHT is diagnosed in an individual with PAVMs, broadly speaking, each of their first-degree relatives (child, sibling and parent) has a $50 \%$ chance of having $\mathrm{HHT}$, and at least $50 \%$ of HHT-affected relatives are expected to have PAVMs. ${ }^{15-7}$ Establishing an HHT diagnosis in the family is therefore critical for optimal management of the greatest number of individuals.

A definite clinical diagnosis of HHT requires three of four Curaçao criteria, namely, recurrent spontaneous nosebleeds, mucocutaneous telangiectasia at characteristic sites, visceral involvement (such as gastrointestinal telangiectasia or pulmonary, hepatic, cerebral or spinal arteriovenous malformations) and a positive family history. ${ }^{6} 8$ Many consider that if HHT is present, these clinical features will be clearly evident and do not appreciate the importance of suspecting the diagnosis and offering HHT management to patients with one or two criteria as recommended ${ }^{68}$ (online supplemental data 1). This issue was exemplified by the April 2020 release of the National Health Service (NHS) National Genomic Test Directory (online supplemental data 1). For a patient who is the first of their family considered for HHT (the proband), HHT gene testing eligibility was contingent on them already having three Curaçao criteria, that is, a definite clinical diagnosis of HHT. Thus, patients with PAVMs were only eligible if they had two further Curaçao criteria from nosebleeds, telangiectasia and a family history of HHT.

\section{RETROSPECTIVE REVIEW}

To address if under-recognition of HHT could compromise personal management or predictive testing for relatives, we retrospectively reviewed data on the 208 unrelated adults genetically tested for HHT through NHS clinical diagnostic testing via gene panels or 100, 000 Genomes Project wholegenome sequencing in two UK centres (Liverpool, 2007-2019, and Imperial, 2015-2019). Many had clear-cut HHT, for instance, 14 of 27 (52\%) Liverpool patients and 123 of 181 (68\%) Imperial patients had a definite diagnosis of HHT, meeting three Curaçao Criteria. ${ }^{8}$ Of the 208 patients, 124 were unrelated adults with PAVMs managed at the PAVM reference centre at Hammersmith Hospital.

The genes most frequently harbouring HHTcausal variants are ENG, ACVRL1 and SMAD4, when patients are heterozygotes with one wild type (normal) allele and one loss-of-function variant allele. ${ }^{7}$ Of the 208 unrelated adult probands undergoing genetic testing for suspected HHT across the two centres, at the time of analysis, 152 (73\%) had a causative variant identified through NHS clinical diagnostic testing. Only 104 (68\%) of 152 patients with genetically confirmed HHT due to ENG, ACVRL1 or SMAD4 met three criteria for a definite clinical diagnosis of HHT. As detailed in figure 1, 48/152 (32\%) genetically diagnosed patients with 
A

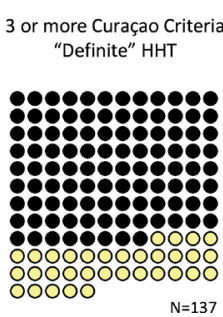

B

1 or 2 Curaçao Criteria

"Unlikely/possible" HHT

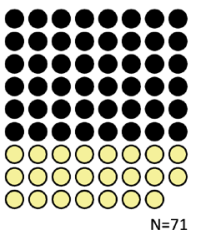
- Causal HHT variant identifiec
No HHT variant identified

Fisher's exact test $\mathrm{p}=0.25$

Figure 1 Genotype-phenotype analyses in 208 genotyped patients with HHT. Proportion of genotyped patients with (black) and without (pale yellow) causal HHT variant identification, if (A) meeting three Curaçao criteria for 'definite $\mathrm{HHT}^{\prime}$ ' (B) meeting one to two Curaçao criteria. The Curaçao criteria are spontaneous, recurrent nosebleeds; multiple telangiectasia at characteristic sites (lips, oral cavity, fingers and nose); visceral lesions such as gastrointestinal telangiectasia (with or without bleeding), pulmonary AVM, hepatic AVM, cerebral AVM, spinal AVM and a first-degree relative with $\mathrm{HHT}$ according to these criteria. ${ }^{8} \mathrm{AVM}$, arteriovenous malformation; $\mathrm{HHT}$, hereditary haemorrhagic telangiectasia.

HHT met only one or two criteria, most commonly a PAVM, though many had a family history of nosebleeds over several generations without diagnosis of a relative with HHT (figure 2). Furthermore, the rate of a positive HHT genetic test in the 137 patients already meeting a clinical diagnosis of HHT with three Curaçao criteria $(104 / 137,76.0 \%)$ was no higher than that in the 71 patients with fewer than three Curaçao Criteria (48/71, $68 \%, \chi^{2} \mathrm{p}=0.25$; figure 1 ).

Focussing on the cohort of 124 unrelated adults with PAVMs who were the first in their family to have a gene test, 83 (67\%) were found to be heterozygous for a likely pathogenic or pathogenic variant in ENG, ACVRL1 or SMAD4, that is, confirmed to have HHT. However, HHT was not always clinically apparent: while 63/83 (76\%) of patients with PAVMs and genetically confirmed HHT met three or more Curaçao criteria, 20/83 (24\%) displayed little evidence of HHT, including patients with single PAVMs. None of these 20 met the family history HHT criterion; only $3 / 20(15 \%)$ had classical HHT telangiectasia, and although some reported occasional or regular nosebleeds, PAVMs could be the only HHT feature across two genetically confirmed generations.

Family history only positive for

i) Nosebleeds

ii) Pulmonary or cerebral AVM(s)

Patient meets only one of:

iii) 1CC: Pulmonary AVM(s)

iv) 1CC: Two or more HHT-site AVMs

v) $2 \mathrm{CC}$ : $\mathrm{HHT}$-site $\mathrm{AVM}$ plus $1 \mathrm{CC}$

vi) $2 \mathrm{CC}$ : $\mathrm{HHT}$ telangiectasia plus $1 \mathrm{CC}^{\mathrm{T}}$

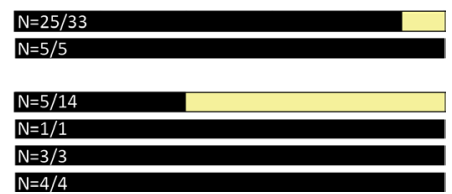

Figure 2 Genotype-phenotype analyses in subgroups of genotyped patients with HHT who did not meet the threshold for a clinical diagnosis of HHT. Proportion of genotyped patients with (black) and without (pale yellow) causal HHT variant identification, if meeting the stated patterns. 1CC from spontaneous, recurrent nosebleeds; multiple telangiectasia at characteristic sites (lips, oral cavity, fingers and nose); visceral lesions such as gastrointestinal telangiectasia (with or without bleeding) or HHT-site AVMs (pulmonary AVM, hepatic AVM, cerebral AVM and spinal AVM); and a first-degree relative with HHT according to these criteria. ${ }^{8} 1 \mathrm{CC}^{\top}$ : severe nosebleeds requiring blood transfusions. 1CC, 1 Curaçao criteria; AVM, arteriovenous malformation; HHT, hereditary haemorrhagic telangiectasia.

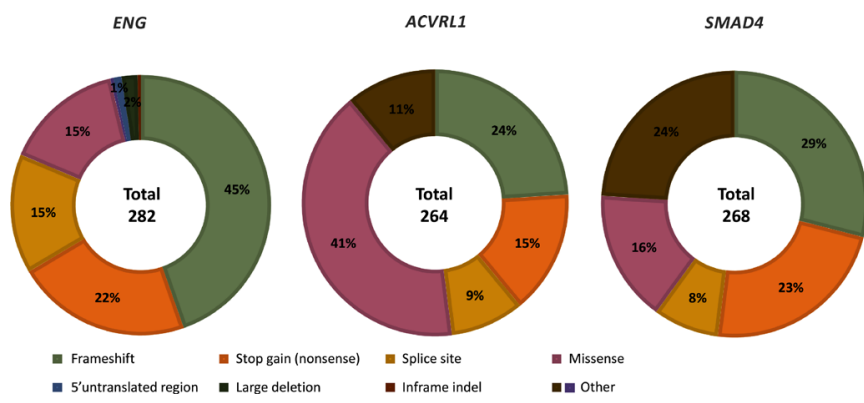

Figure 3 Causal HHT variants on ClinVar. The distribution of 814 unique likely pathogenic and pathogenic variants in $E N G, A C V R L 1$ and SMAD4 listed in ClinVar. ${ }^{9}$ Loss-of-function variants meeting very strong evidence of pathogenicity include frameshifts (green) due to an out-offrame insertion or deletion (indels), nonsense (stop gain) substitutions generating a premature stop codon and splice site variants affecting the exon-flanking consensus $( \pm 1$ and \pm 2 ) splice sites. Missense variants (purple) where a single amino acid is substituted represent a higher proportion of pathogenic and likely pathogenic variants in ACVRL1 than ENG or SMAD4 (109/264 (41\%) compared with 85/550 15.5\%) for ENG/ SMAD4 ( $\mathrm{p}<0.0001$, Fisher's exact test). HHT, hereditary haemorrhagic telangiectasia.

\section{IMPLICATIONS}

Based on these data, and supported by the British Thoracic Society, other specialist societies, patient groups and expert clinicians, the NHS Genomic Test Directory was amended to allow HHT gene testing for patients with one or more PAVMs (online supplemental data 1). Proposing an HHT genetic test is important for respiratory and radiological clinicians treating a patient with PAVMs. Additionally, up to 20\% of PAVMs referred for embolisation are incidental findings on imaging (Alsafi A and Shovlin CL, unpublished data 2022), and it is important that the reporting radiologist raises the high likelihood of its association with HHT, which may otherwise go unrecognised. Referring clinicians will receive gene test reports that may identify one of multiple HHT causal DNA variants. Currently, ClinVar lists 2804 different variants across the three major HHT genes, with 814 different variants classified as pathogenic or likely pathogenic (figure 3). ${ }^{9}$ The presence of one such variant defines the individual as having HHT, whether or not they or their family have clinical features. Importantly, however, unless the genetic variant has already been identified for the family, the converse is not true, and a negative gene test does not exclude HHT. These false-negative tests may reflect the presence of an unreported DNA variant that did not meet sufficient molecular criteria to be reported as likely pathogenic ${ }^{10}$ or an undetected DNA variant in an uncaptured region of the genome. Thus, for a patient with one or more PAVMs without a positive genetic test for HHT, screening first-degree relatives once in adult life for PAVMs remains good practice, as in the British Thoracic Society Clinical statement. ${ }^{1}$

\section{CONCLUSION}

One-third of adult patients with genetically confirmed HHT and one-quarter of adult patients with PAVMs and genetically confirmed HHT did not meet clinical diagnostic criteria for HHT. Gene testing is an efficient route to establish the diagnosis of HHT, whether or not HHT is clinically apparent, and is now an important component of care for patients with one or more PAVMs. 
Acknowledgements We thank our colleagues in the Genomic Medicine, HHT and PAVM services at Imperial College Healthcare National Health Service (NHS) Trust and the Liverpool Centre for Genomic Medicine. We also thank the supporters of our January 2021 National Genomic Test Directory Amendment proposal: the British Thoracic Society, the British Rhinological Society, ENT-UK, the British Society for Gastroenterology Liver Section, the British Association for the Study of the Liver, the NHS Hereditary Haemorhagic Telangiectasia Rare Disease Collaborative Network, the Telangiectasia Self Help Group, HHT UK and the 40 consultants with HHT expertise who supported the amendment. This research was made possible through access to the data and findings generated by the 100,000 Genomes Project. The 100,000 Genomes Project is managed by Genomics England Limited (a wholly owned company of the Department of Health and Social Care). The 100,000 Genomes Project is funded by the National Institute for Health Research and NHS England. The Wellcome Trust, Cancer Research UK and the Medical Research Council have also funded research infrastructure. The 100,000 Genomes Project uses data provided by patients and collected by the National Health Service as part of their care and support. The views expressed are those of the authors and not necessarily those of funders, the NHS, the NIHR, or the Department of Health and Social Care.

Contributors EA was responsible for conception and design, acquisition analysis and interpretation of Liverpool data; performed data analysis; and contributed to manuscript writing and revision. LS examined ClinVar data, generated figure 3 and contributed to manuscript revision. AA was responsible for PAVM patient review, treatment and radiological management insights. CLS was responsible for planning, conception and design, acquisition analysis, and interpretation of Imperial data; supervised LS; performed data analysis; wrote the manuscript; generated figures 1 and 2; and contributed to manuscript revision. All authors approved the final manuscript.

Funding Funding was received from the National Institute of Health Research Biomedical Research Centre Scheme (Imperial BRC) and Imperial College Faculty of Medicine BSc project funds (to CLS for LS). The views expressed are those of the authors and not necessarily those of funders, the NHS, the National Institute for Health Research or the Department of Health and Social Care.

Competing interests The authors have no financial competing interests to declare. CLS chairs the Genomics England Respiratory GeCIP, the North Thames Genomic Medicine Service Alliance R\&D Committee, the NHS Hereditary Haemorhagic Telangiectasia Rare Disease Collaborative Network and the British Thoracic Society Pulmonary AVM Clinical Statement Group; sits on the Cure HHT Global Research and Medical Advisory Board, the ClinGen Hereditary Hemorrhagic Telangiectasia Variant Curation Expert Panel; and chaired the European Reference Network for Rare Multisystemic Vascular Diseases HHT Working Group 2016-2020.

Patient consent for publication Not applicable.
Provenance and peer review Not commissioned; externally peer reviewed.

Open access This is an open access article distributed in accordance with the Creative Commons Attribution Non Commercial (CC BY-NC 4.0) license, which permits others to distribute, remix, adapt, build upon this work non-commercially, and license their derivative works on different terms, provided the original work is properly cited, appropriate credit is given, any changes made indicated, and the use is non-commercial. See: http://creativecommons.org/licenses/by-nc/4.0/.

\section{ORCID iDs}

Emily Anderson http://orcid.org/0000-0002-0202-4028

Lakshya Sharma http://orcid.org/0000-0002-3509-6140

Ali Alsafi http://orcid.org/0000-0001-6688-8637

Claire L Shovlin http://orcid.org/0000-0001-9007-5775

\section{REFERENCES}

1 Shovlin CL, Condliffe R, Donaldson JW, et al. British Thoracic Society Clinical Statement on pulmonary arteriovenous malformations. Thorax 2017;72:1154-63.

2 Nakayama M, Nawa T, Chonan T, et al. Prevalence of pulmonary arteriovenous malformations as estimated by low-dose thoracic CT screening. Intern Med 2012;51:1677-81.

3 Topiwala KK, Patel SD, Saver JL, et al. Ischemic stroke and pulmonary arteriovenous malformations: a review. Neurology 2022;98:188-98. doi:10.1212/ WNL.0000000000013169

4 Müller-Hülsbeck S, Marques L, Maleux G, et al. CIRSE standards of practice on diagnosis and treatment of pulmonary arteriovenous malformations. Cardiovasc Intervent Radiol 2020;43:353-61.

5 Faughnan ME, Mager JJ, Hetts SW, et al. Second International guidelines for the diagnosis and management of hereditary hemorrhagic telangiectasia. Ann Intern Med 2020;173:989-1001.

6 Shovlin CL, Buscarini E, Sabbà C, et al. The European Rare Disease Network for HHT Frameworks for management of hereditary haemorrhagic telangiectasia in general and speciality care. Eur J Med Genet 2022;65:104370.

7 Shovlin CL, Simeoni I, Downes K, et al. Mutational and phenotypic characterization of hereditary hemorrhagic telangiectasia. Blood 2020;136:1907-18.

8 Shovlin CL, Guttmacher AE, Buscarini E, et al. Diagnostic criteria for hereditary hemorrhagic telangiectasia (Rendu-Osler-Weber syndrome). Am J Med Genet 2000;91:66-7.

9 Landrum MJ, Chitipiralla S, Brown GR, et al. ClinVar: improvements to accessing data. Nucleic Acids Res 2020;48:D835-44.

10 Davieson CD, Joyce KE, Sharma L, et al. DNA variant classification-reconsidering "allele rarity" and "phenotype" criteria in ACMG/AMP guidelines. Eur J Med Genet 2021;64:104312. 